\title{
E-POSLOVANJE U SPORTSKIM ORGANIZACIJAMA
}

\author{
Milan Gašović*, \\ Radovan llić
}

Univerzitet Singidunum, Beograd, Srbija

Odgovorno lice:

Milan Gašović

e-pošta:

mgasovic@singidunum.ac.rs
Rezime:

Poslovanje u sportu je ekonomsko poslovanje sportskih organizacija (klubova, saveza, udruženja) koje je delom identično sa poslovanjem drugih tipova organizacija, a delom različito zbog specifičnosti samog sporta. E-poslovanje je svaki oblik poslovne transakcije u kojoj učesnici pripremaju ili obavljaju posao elektronskim putem. E-sportsko poslovanje ima za pretpostavku transakcije koje obavljaju sportske organizacije putem Interneta. Glavni aspekti e-poslovanja u sportu su: komercijalno e-poslovanje; obrazovno eposlovanje; uslužno e-poslovanje i sl. Uobičajeni instrumenti preko kojih se odvija e-poslovanje u sportu su sportski portali ili stranice.

Ključne reči:

informaciono-komunikacione tehnologije, sportske organizacije, e-poslovanje, komercijalni sportski portali, obrazovni sportski portali.

\section{UVOD}

Savremene sportske organizacije već skoro četiri decenije imaju mogućnost korišćenja tehnologija koje mogu unaprediti njihovo poslovanje. Radi se,pre svega o veoma efikasnim mrežnim računarima, uslugama digitalne TV, personalnim digitalnim uređajima i inteligentnim uređajima kod kuće i u kancelariji.

Pored već tradicionalne upotrebe informacione tehnologije kao što je korišćenje računara i pridruženih mreža koji omogućavaju aplikacije za stolom (obrada teksta; analiza tabela i upravljanje bazom podataka), ovaj rad je usredsređen na elektronsko (e-poslovanje) sportskih organizacija (klubova,udruženja,saveza) koje se obavlja preko mreža koje koriste nezaštićene (nevlasničke) protokole, kao što je Internet [1].

Neophodna pretpostavka za razvoj sportskog e-poslovanja je sve masovnija upotrebe Interneta i unapređenje sistema upravljanja informacijama. Isto tako, omogućen je slobodan pristup globalnoj intrnet mreži uz relativno nisku cenu, kao i korišćenje postojeće komunikacione infrastrukture Pri tom,većina osoba može lako pristupiti Internetu. Isto tako, nove tehnologije pružaju mogućnosti komunikacija po sistemu "jedan prema mnogima” i "mnogi prema mnogima”, kao i prenos informacija kroz različite uređaje. 
Polazeći od vrste transakcija sportsko, kao i ostale vrste e-poslovanja mogu se razmatrati na sledeći način: B2C (Business to consumer - biznis kompanija prema krajnjem potrošaču), B2B (Business to Business - biznis kompanija prema biznis kompaniji), C2C (Consumer to Consumer - potrošač prema potrošaču) i C2B (Consumer to Business - potrošač prema biznis kompanijama $[2]$.

E-poslovanje sportskih organizacija obuhvata nekoliko aspekata, kao što su: komercijalno sportsko poslovanje; obrazovno sportsko poslovanje i uslužno sportsko poslovanje [3].

Komercijalno e-poslovanje sportskih organizacija se odvija putem komercijalnih sportskih stranica ili portala koje nude sadržaje fokusirane na ostvarenje prihoda preko oglašavanja, prodaje ulaznica i prodaje za sport vezanih proizvoda.

Obrazovno e-poslovanje sportskih organizacija se realizuje preko obrazovanih sportskih stranica, odnosno portala koji omogućavaju korisnicima prijavu za edukaciju, vežbanje i treniranje.

Uslužno e-poslovanje sportskih organizacija ima za pretpostavku postojanje uslužnih stranica ili portala putem kojih se pružaju usluge navijačima, članovima i simpatizerima. Njima se dostavljaju sadržaji koji prikazuju rasporede mečeva, rezultate itd.

\section{POJAM I KARAKTERISTIKE E-POSLOVANJA SPORTSKIH ORGANIZACIJA}

Poslovanje sportskih organizacija (klubova, saveza, udruženja) je, u stvari ekonomsko poslovanje koje je delimično slično poslovanju drugih tipova organizacija, ali i različito jer je sam sport specifična ljudska aktivnost. Postoji tradicionalno ili oflajn poslovanje i elektronsko ili onlajn poslovanje sportskih organizacija.

Elektronsko poslovanje ili e-poslovanje sportskih organizacija obuhvata sve oblike poslovnih transakcija u kojima učesnici pripremaju ili obavljaju posao elektronskim putem. Radi se kako o jednostavnim interakcijama kao što su slanje e-pošte poslovnim saradnicima od kojih se traže informacije o predstojećem sportskom događaju, tako i o onlajn kupovini ulaznica, za sport vezanih proizvoda ili posmatranja datog događaja kod kuće.

Jedan broj autora koji se bavi sportskim poslovanjem, posmatra e-poslovanje i e-trgovinu kao dve različite aktivnosti [1].
Elektronsko poslovanje je uglavnom, fokusirano na komunikaciju sa klijentima i partnerima, kao i korišćenje tehnologija koje omogućavaju proces poslovanja.

Elektronska trgovina može uključivati sve oblike finansijskih i komercijalnih transakcija poput elektronske razmene podataka (Electronic Data Interchange, EDI), elektronskog prenosa sredstava (Electronic Funds Transfer EFT), kao i aktivnosti debitnih i kreditnih kartica.

Polazeći od tipa transakcija, poznata su četiri glavna oblika e-poslovanja i to: B2C; B2B; C2C; C2B koji se primenjuju i na sportsko e-poslovanje[2].

B2C (Business to Consumer - kompanija prema krajnjem potrošaču) je oblik e-poslovanja, odnosno onlajn trgovine ili B2C stranice za kupovinu koje pružaju dodatni kanal za prodaju postojećim ili novim kompanijama ili direktan, stalan pristup kupcima. Kada je u pitanju područje sporta , kao primeri se mogu naznačiti informativne stranice za ograničena tržišta poput sportskih događaja, podataka o timovima i stranice navijača.

B2B (Business to Business - kompanija prema kompaniji) oblik je e-poslovanja koji ima za pretpostavku B2B internet stranicu putem koje se nastoji kreirati „virtuelni lanac snadbevanja”. Naime, elektronski se povezuju dobavljači, distributeri, preprodavci i ugovarači, kako bi stvorili protok informacija. Kada su u pitanju primeri iz sporta, to je sportnet.

$\mathrm{C} 2 \mathrm{C}$ (Consumer to Consumer - potrošač prema potrošaču) je oblik e-poslovanja uz podršku C2C stranica preko kojih potrošači (klijenti) mogu direktno međusobno delovati kako bi razmenjivali informacije, proizvode i usluge. Primeri iz sporta su stranice - memorablije za obožavaoce sporta.

C2B (Consumer to Bussiness - potrošač prema kompaniji), oblik je e-poslovanja koji omogućava da uz pomoć internet stranice pojedinci mogu ponuditi profesionalne usluge drugima. C2B dopušta klijentu kontrolu transakcija pomoću procesa kao što je „obrnuta akcija”, kada ponuđač postavlja cenu za proizvode ili usluge i zahteva nadmetanje (aukcija).

Prema Beeshu i Chadviku [1] tri su glavne aspekta sportskog e-poslovanja su:

- Komercijalni aspekt e-poslovanja

- Obrazovni aspekt e-poslovanja

- Uslužni aspekt e-poslovanja. 
Komercijalni aspekt e-poslovanja u sportskim organizacijama

Komercijalni aspekt e-poslovanja sportskih organizacija ima za pretpostavku postojanje tzv. komercijalnih sportskih stranica ili portala. Date stranice služe kao „prozor” za navijače ili druge korisnike iz oblasti sportskog auditorijuma (navijači, članovi, simpatizeri, mediji, sponzori, oglašivači, drugi klubovi, partneri, savezi, lige, akcionari, agenti i sl.) [2]. Početni cilj datih sportskih portala je da budu informacione stranice za navijače.

Sportski portali, obično pružaju besplatne usluge korisnicima, kao što su: pretraživanja, lokalne, nacionalne i svetske sportske vesti, e-pošta, pričaonica (chat rooms), vremenska prognoza i važeći sportski rezultati [1].

Neki portali ili stranice se mogu podesiti, odnosno prilagoditi ličnim željama, tako da obožavaoci nekog tima ili sportiste pojedinca, dobijaju informacije samo o njima. Sličan primer takvog portala je specijalizovani portal pod nazivom adventure-sport.com, koji nudi sve potrebne informacije zainteresovanim osobama za aktivnosti u prirodi.

Portal adventure-sport.com, pruža usluge i turističkim organizacijama, kao i omogućavanje pristupa istomišljenicima kroz različite interesne zajednice.

Sportski portal su postali veoma popularni i pogodni da preko njih sportske organizacije ostvaruju prihode kroz oglašavanje, pretplatu i prodaju za sport vezanih proizvoda i usluga.

Vlade nekih zemalja ulažu znatna sredstva u sportske portale. Tako npr, portal sportengland.com predstavlja inicijativu Vlade Velike Britanije sa ciljem razvoja sporta [1].

Kompanija Nike je među prvima kreirala svoju komercijalnu stranicu, odnosno portal nike.com. Tada je perspektiva B2C servisa bila neizvesna. Stranica je bila samo onlajn brošura i nije imala nikakve dodatne aktivnosti kada je u pitanju e-poslovanje. Glavna funkcija nike.com portala bila je isticanje brenda Nike. Bio je podeljen na odvojene stranice i zasnovano na širokom spektru opreme i sportova u kojima je kompanija imala udeo [1].

Portal nike.com se kasnije integrisao u svetski kanal e-poslovanja ili e-marketinga. Od tada postoje višestruke stranice proistekle iz glavne stranice, orijentisane prema zemlji porekla i mogućnosti izbora jezika od strane korisnika.

Nike.com portal zainteresovani korisnici mogu posetiti prema vrsti sporta ili aktivnosti koja ih interesuje.
Delpy i Bosett [4] ukazuju da svi profesionalni klubovi u SAD imaju svoju internet stranicu ili portal. Većina datih stranica je međusobno umrežene preko uprava liga u kojima se takmiče dati klubovi. Navedena povezanost sa protivničkim klubovima je delimično uslovljena dogovorima između klubova vezano za podelu prihoda od tv prenosa, kao i prodaje za sport vezanih proizvoda.

Početkom XXI veka sportski portali su se najčešće oslanjali na model poslovanja fokusiran na oglašavanje koje je bilo moguće putem otkupa prava na prikazivanje sportskih događaja ili plaćenim oglasima sponzora tih događaja na stranici.

Pored oglašavanja na portalima, neke stranice su koristile i sportske zvezde kako bi povećale svoje poslovne mogućnosti.

Međutim, fokusiranost sportskih portala samo na oglašavanje kao izvor prihoda, kao i nepostojanje strategijskih pravaca razvoja, doveo je do bankrota nekih od njih.

Dosadašnja praksa e-poslovanja sportskih organizacija ukazuje da će na sportskom onlajn tržištu opstati oni sportski portali koji budu kreirali stranice sa jedinstvenim sadržajem i koji izgrade snažnu korisničku zajednicu. Pri tom moraju biti prepoznatljivi po interaktivnosti, sportskim ličnostima i onlajn pravima.

\section{Obrazovni aspekt e-poslovanja u sportskim organizacijama}

Pored korišćenja Interneta u komercijalne svrhe, sportsko e-poslovanje se početkom XXI veka počelo razvijati i u drugim pravcima, kao što je onlajn sportsko obrazovanje, poučavanje (obuka) i trening [5].

Sportski treneri koriste Internet iz različitih razloga, što uključuje:

- pretraživanja vezana za nove trendove,teme i ideje na području treninga i obuke,

- komunikacija sa kolegama i sportistima,

- informacije o protivničkim timovima, trenerima i lokacijama,

- informacije o vremenu, prevozu i smeštaju.

Internet omogućava trenerima i sportistima analizu i sintezu informacija i uslova kako bi se poboljšali treninzi, donošenje odluka i razvoj.

Primer za upotrebu internet tehnologije za upravljanje izvođenjem(igrom) timova je digitalni sistem, poznat kao DSV Capture softver. Upotrebljava se za snimanje i reprodukciju video-zapisa koji koriste profesionalni 
kriket timovi gde se sačuvani podaci mogu analizirati u realnom vremenu dok se igra odvija. Dati podaci su dostupni igračima i trenerima na bilo kom mestu na sportskom borilištu. Izveštaji se mogu odmah napraviti, a podaci sačuvati za kasnije preuzimanje [6].

Internet tehnologija može uticati na masovno učestvovanje u sportu i promociju društvenog uključivanja. Instrumenti za obradu podataka i sistema korisni su sportskim menadžerima, posebno u području upravljanja sportskim događajima.

Internet tehnologija može biti od pomoći kako istraživačima poslovanja u sportu i menadžmenta u sportu, tako i studentima koji mogu da koriste oglasne ploče, da šalju zadatke i preuzimaju beleške sa predavanja.

Korišćenje elektronskih podataka u sportskim organizacijama,može se i tabelarno prestaviti (Tabela 1).

\begin{tabular}{cl}
\hline $\begin{array}{c}\text { Sportski subjekti } \\
\text { i aktivnost }\end{array}$ & \multicolumn{1}{c}{ Sadržaj baze podataka } \\
\hline $\begin{array}{c}\text { Timovi i sportisti- } \\
\text { pojedinci }\end{array}$ & $\begin{array}{l}\text { Demografski podaci: Ime, prezime, } \\
\text { starost, pol, kontakt podaci, medicin- } \\
\text { ski detalji, istorijat karijere }\end{array}$ \\
\hline Trening/obuka & $\begin{array}{l}\text { Treninzi i kondicioni } \\
\text { treninzi, rasporedi }\end{array}$ \\
\hline
\end{tabular}

Popisi dobavljača, zaposlenih, popis opreme i zaliha, softverski paketi

Menadžment za upravljanje objektima, podaci o prodaji karata, računovodstveni zapisi i zapisi o poslovanju

Marketing Donatori, sponzori, oglašivači

Tabela 1

Informacione tehnologije imaju i druge primene, kao što je model poznat kao VRML (Virtual Reality Modeling Language). Radi se o kreiranju virtuelne atletske prostorije za trening koja pomaže prilikom obuke samih trenera. Dati model je važan za trenere kao obrazovni instrument koji uključuje i primenu mera za oporavak njihovih sportista posle napornih takmičenja [7].

Isto tako, razvijeni su i softveri za razvoj ličnih planova aktivnosti za poboljšanje zdravlja. Dati softver se sastoji od internet stranica koje korisnike edukuju o ideji welnesa i kreiranju ličnog welness plana. Takođe, kada se radi o sportskoj edukaciji, moguća je i analiza igre, elektronsko vođenje dnevnika treninga i primena raznih ručnih sprave za beleženje uspešnosti sportista.
Uslužni aspekt e-poslovanja u sportskim organizacijama

Uslužno e-poslovanje kao kategorija poslovanja u sportu zasniva se na sportskim portalima ili stranicama usmerenim na usluge. Na taj način sportske organizacije pružaju usluge akterima velikog sportskog auditorijuma tako što im se dostavlja sadržaj, rasporedi i rezultati utakmica itd. Pri tom je ključna usmerenost na informacije, na zajednicu, kao i na virtuelne zajednice.

Međutim, portali i stranice sportskih organizacija se razlikuju po profesionalnom pristupu, sadržaju, karakteristikama i namenama.Takođe, koriste se različiti onlajn modeli kao što je web costing ili dizajnerske agencije koje kreiraju bazične internet stranice. Date stranice, najčešće pružaju informacije o pojedinim igračima, izjavama za štampu, prodaji ulaznica, članskih i sezonskih karata, kao i ponudi za sport vezanih proizvoda. Isto tako nude galeriju fotografija i statističke podatke iz oblasti sporta.

Neophodna pretpostavka za poboljšanje sportskih usluga jeste strategijski pristup datim aktivnostima od strane sportskih organizacija, kao i adekvatna informaciona struktura. Takođe, nužno je i integrisanje onlajn i oflajn strategija kako bi se povećala uključenost društvene zajednice u sport [8].

Strategijski pristup uslugama može rezultirati održivom onlajn platformom za navijače i članove sportskih organizacija. Pri tom, sportske organizacije treba da se fokusiraju na sledeća glavna područja prilikom kreiranja korisnog i privlačnog sadržaja sportskih portala ili stranica [1].

- Mogućnost pristupa navijačima, odnosno njihovim grupama ili zajednicama, kako bi se izašlo u susret njihovim, kako opštim, tako i specifičnim potrebama.

- Kreiranje sportskih portala ili stranica koje mogu privući globalnu publiku

- Bolje korišćenje novih onlajn tehnologija

- Zadržavanje navijača i članova sportskih organizacija na portalima putem promovisanja i korišćenja navijačkih rituala.

Postojanje strategije e-poslovanja sportskih organizacija je baza za razvoj onlajn resursa putem kojih se pružaju usluge korisnicima iz područja velikog sportskog auditorija. Preko strategije se pokazuje ozbiljnost pristupa i osobenost njihovih stranica ili portala.

Strategijske mogućnosti sportskih organizacija u oblasti e-poslovanja u direktnoj su vezi sa privlačnošću i osobenostima njihovih stranica ili portala. 


\section{ZAKLUČAK}

Sveopšta upotreba Interneta i stalan napredak u korišćenju informaciono-komunikacionih tehnologija uticali su na promenu načina na koji sportske organizacije predstavljaju svoju ponudu velikom sportskom ciljnom auditorijumu (navijačima, članovima, simpatizerima, medijima, oglašivačima, sponzorima, partnerima, proizvođačima za sport vezanih proizvoda/usluga, sportskim agentima, potencijalnim kupcima akcija itd.)

Drugim rečima, upotreba Interneta i uključivanje informativno-komunikacionih tehnologija u poslovanje sportskih organizacija donelo je nove izazove čije savladavanje ima za pretpostavku izbor adekvatnih modela e-poslovanja.

Razvoj e-poslovanja u sportskim organizacijama je iskristalisao tri aspekta: komercijalni, obrazovni i uslužni.

Komercijalni aspekt e-poslovanja se obavlja preko komercijalnih sportskih stranica ili portala. Dati portali su u početku bili kreirani tako da navijačima, članovima i simpatizerima pruže najnovije informacije iz sportske organizacije zatim lokalne, nacionalne i svetske vesti i sportske rezultate .Međutim, nagli rast popularnosti sportskih portala je omogućio sportskim organizacijama da stiču značajne prihode putem oglašavanja i prodaje za sport vezanih proizvoda i usluga.

Obrazovni aspekt e-poslovanja u sportskim organizacijama zahteva kreiranje obrazovnih stranica ili portala koji omogućavaju onlajn sportsko obučavanje i trening. Sportski treneri su u mogućnosti da pretražuju obrazovne portale, prate nove trendove u pripremi i vođenju ekipa i sportista-pojedinaca, komuniciraju sa kolegama, prate rezultate i dešavanja u protivničkim ekipama i sl.

Uslužni aspekt e-poslovanja sportskih organizacija ima za pretpostavku postojanje uslužnih stranica ili portala. Date stranice pružaju korisnicima (navijačima, članovima, simpatizerima, medijima itd.) usluge kao što su: informacije o najnovijim dešavanjima u klubu; izjave čelnika; prodaja ulaznica, članskih i sezonskih karata; prodaja za sport vezanih proizvoda i usluga i sl.
Izazovi sa kojim se suočavaju sportske organizacije kada se radi o e-poslovanju zahtevaju strategijski pristup za njihovo savladavanje. Pre svega, mora se jasno ustanoviti koji delovi njihovog ranijeg poslovanja prelaze na onlajn kanal. Isto tako, nužno je sagledati kako će novi onlajn kanal poslovanja biti uklopljen u postojeće oflajn poslovanje.

Rešavanje navedenih problema je u direktnoj zavisnosti od ustanovljene strategije e-poslovanja, pažljivo izabranih modela i znanja i veština zaposlenih i menadžera u sportskim organizacijama.

\section{LITERATURA}

[1] J. Beech, S. Shadwick, Sportski menadžment, Zagreb: Mate, 2010.

[2] M. Gašović, Marketing sportskih organizacija, Beograd: IntermaNet, 2009.

[3] L. R. Kahle, L. Meeske, Sport Marketing Quartely, Vol. 8. No. 2, 2009. pp. 10-12.

[4] D. Delpy, H, Bosetti, Sport management and marketing via the world wide web", Sport Marketing Quartely,Vol. 7, No. 1, 2009, pp. 21-27.

[5] R. Taylor, Coach Education in the 21st century: challenges and opportunities, International Coach Education Conference Proceedings, Canberra, 2007.

[6] B. Rushal, The Internet and coaching education, International Coach Education Conference Proceedings, Canberra, 2009.

[7] B.E. Holcomb, The Virtual athletic training room, magistarska teza, San Jose University. 2007.

[8] C. O. Berine, S. Stoney, Scoring goals: strategic application of the Internet by Western Australian sport Organization, Proceedings of the 2nd International We-B Conference, 11, Australia 2011. 